\title{
TELEDENTISTRY AS POTENTIAL OPPORTUNITY FOR THE IMPROVEMENT OF DENTAL CARE IN PERIODS OF SOCIAL ISOLATION: PRELIMINARY RESULTS OF LITERATURE REVIEW
}

\author{
Krzysztof A. Gebczynski', Joanna Zarzecka', Joanna Słowik²
}

'Department of Conservative Dentistry with Endodontics, Institute of Dentistry, Faculty of Medicine, Jagiellonian University Medical College, Poland ${ }^{2}$ Department of Dental Prophylaxis and Experimental Dentistry, Jagiellonian University Medical College, Krakow, Poland

\begin{abstract}
The literature on teledentistry and telemedicine was reviewed in the PubMed (302) and Embase (131) bases, using following keywords and their combinations: "iPad", "tablet", "cell phone", "smartphone”, "mouth hygiene”, "oral hygiene", "dental hygiene", "mouth care", "mouth washing", "mouth rinsing", "tooth hygiene", "oral health", "mobile applications", "app", "mobile app", "teledentistry", "telemedicine". Non-English written articles and those published before 1995 were excluded from the review.

Forms of remote contact in conditions of social isolation may prove to be among the most effective methods supporting medical care for patients.

Telemedicine is a multidimensional concept, signifying the provision of medical services (healthcare) and medical education as well as conducting scientific research, using telecommunication and IT tools. The COVID-19 pandemic has presented unprecedented challenges at every level of public life, including that of ensuring the safety of medical care. Dentists, in their daily practice, are among the most vulnerable professional groups. During the pandemic period, in addition to many restrictions regarding the provision of health services, teleconsultation prior to admission of the patient to the dental surgery is recommended. In a condition of social isolation, archived or real-time as well as radiographic images of clinical status would greatly facilitate the correct diagnosis and monitoring of the treatment process. Additionally, these images enable training of medical staff, implementation of pre- and post-graduate curricula, and conducting scientific research.
\end{abstract}

KEY wORDS: telemedicine, dental health services, teledentistry, COVID-19, public health dentistry.

J Stoma 2020; 73, 6: 351-354

DOI: https://doi.org/10.5114/jos.2020.102054

\section{INTRODUCTION}

The COVID-19 pandemic poses exceptional challenges at every level of social life, including that of ensuring the safety of medical care. Dentists, in their daily practice, constitute one of the most vulnerable professional groups due to close contact with patients, particularly with their respiratory tracts. Saliva and fine particles from the respiratory system suspended in air are spread through the use of high-speed turbines in the form of an aerosol throughout the treatment room [1].

During a period of pandemic, apart from many restrictions concerning the provision of health services, teleconsultation prior to admitting the patient to the clinic,
JOURNAL OF STOMATOLOGY CZASOPISMO STOMATOLOGICZNE
AdDress FOR CORRESPONDENCE: Krzysztof A. Gebczynski, Department of Conservative Dentistry with Endodontics, Institute of Dentistry, Faculty of Medicine, Jagiellonian University Medical College, Poland, e-mail: krzysztof.gebczynski@uj.edu.pl

ReCEIVED: 05.10.2020 • ACCEPTED: 05.11.2020 • Published: 30.12.2020 
assuming such a visit is necessary, is recommended (so called "medical triage"). A list of disease entities, in which direct intervention by a dentist is absolutely indicated has also been assessed [2]. During a telephone conversation, it is possible to gather information, determine the risk of infection, and decide whether immediate intervention is required, treatment should be postponed, or appropriate self-care should be recommended to the patient with the implementation of pharmacotherapy via e-prescription. In a state of social isolation, an image of clinical condition, either real-time or archived as well as radiographic images would greatly facilitate the assessment of correct diagnosis and monitoring of the treatment process. The time of pandemic, with forced social isolation, has become an impetus for the development of telemedicine, including teledentistry. It is noteworthy that during the initial period of the pandemic, almost all dental practices were closed.

\section{MATERIAL AND METHODS}

The literature on teledentistry and telemedicine was reviewed in the PubMed (302) and Embase (131) bases, using the following keywords and their combinations: "iPad", "tablet", "cell phone", "smartphone", "mouth hygiene", "oral hygiene", "dental hygiene", "mouth care", "mouth washing", "mouth rinsing", "tooth hygiene", "oral health", "mobile applications", “app", "mobile app", "teledentistry", "telemedicine”. Non-English written articles and those published before 1995 were excluded from the review.

\section{TELEDENTISTRY}

Telemedicine is a multidimensional concept signifying the provision of medical services (healthcare) and medical education as well as conducting scientific research, using telecommunication and IT tools. Specifically, telemedicine represents the capacity to operate remotely, thus reducing distance, saving time, and facilitating contact between medical personnel and patients. Therefore, it is used especially in cases where patients' access to medical facilities (or vice versa, i.e. medical facilities' access to patients) is difficult or impossible. Such situations include catastrophes, wars, natural disasters, transport difficulties, long-time travelling, great distances, heavy demand for medical services, disabilities, a sudden need for a consultation, etc. [3]. The use of new technologies enables the transmission of static and dynamic images, e.g., transmission of the highest quality imaging tests (magnetic resonance imaging, computed tomography, ultrasound, radiological images), measurement and monitoring of vital functions (e.g., cardiovascular telemonitoring), clinical examinations, and intra-operative images, all of which are used in the process of telediagnosis and treatment, in education, and in scientific research.
It has been shown that the main current use of telemedicine are consultations with doctors via video calls, transmission of medical images, and measurements and monitoring of vital signs $[4,5]$. Telemedicine, one of the elements of a wider concept of digital health [6], was used for the first time by the armed forces of the United States of America in the 1960s. Transmission of medical data, necessary consultations, and co-ordination of medical care activities was made possible by a satellite network, connecting military bases located on different continents with medical centers. The next important step in the development of telemedicine was the remote healthcare and health monitoring of NASA astronauts during space missions [6-15]. Teledentistry (TD), likewise telemedicine, was used for the first time by the United States army [6-15], and is slowly being propagated among dentists on a smaller scale $[7,16]$. Given the mobility of the devices being used, teledentistry can be practiced using electronic devices, including applications for mobile phones, tablets, smartwatches, and telemedicine monitoring bands so-called "smart bands" as well as stationary technologies. However, using image recording and playback times as a criterion, teledentistry may be either asynchronous (i.e., involving transmission of archived images of the patient's oral cavity) or synchronous (real-time, with online image transmission) [6].

Practical applications of teledentistry systems involve telediagnosis (consultations with specialists in particular), health monitoring (digital health coaching), and treatment and prevention of diseases of the oral cavity in both asynchronous and synchronous modes. Over a broader range, these applications include screening tests, patients' health education, both pre- and postgraduate medical education (e-learning lectures, webinars, remote examinations using ICT tools, virtual conferences, rapid training depending on situational needs), and management and co-ordination of the work of medical facilities.

Although it can complement and support healthcare systems in stable social conditions, the significance of teledentistry clearly intensifies in situations of destabilization of social systems, such as epidemics, pandemics, or natural disasters [6-8].

Research in recent years indicates many possibilities for the use of teledentistry in clinical practice. To conduct an online visit, all we need is a computer or a mobile phone with a camera, appropriate software, and Internet access. It is also advisable to develop an algorithm for the collection and transmission of data. Real-time teledental consultations must be conducted by means of fully interactive, secure, and bi-directional visual telecommunications systems. The results of these consultations must be documented by an entry in the patient's medical records. It should be emphasized that the transmission of sensitive data is a subject to many restrictions related to legal authorization of procedures as well as, like in our country, a lack of public funding. 
Significant variations can be observed in the development of teledentistry in clinical practice between countries. One example of significant advancement is the United States, where the first public oral health platform, TeleDent was launched in 2016. Through use of this portal, dentists have at their disposal a technology providing the most secure method of transmitting information and, among others, live video conferencing and the capacity to send and archive X-rays [17].

At the beginning of April 2020, teleconsultation services were launched on another oral health platform, SmileMate, which in tandem with a special ScanBox enables consultations with patients. The innovativeness of this method lies in the use of a smartphone accessory, which takes pictures of patient's mouth in appropriate projections [18]. In clinical practice, TD systems can be useful in the treatment of patients with diseases within the range of most dental specialties, including diseases of the oral mucosa $[10,19,20]$ and periodontium $[10$, $14,20]$, malocclusion $[19,20]$, temporomandibular joint disorders, and oral pain [19]. These systems allow for appropriate and early initiation of treatment, contributing to a reduction of complications and treatments' costs [6].

According to the literature, the benefits for patients and treatment centers are higher than the costs incurred, which include expenses related to the training of administrative staff (among others, a care coordinator in charge of establishing a plan of treatment in actual conditions following telemedical consultation), medical staff, hardware and software acquisition, and elimination of barriers related to easy access of patients to telemedicine canters [6].

Teledentistry has also been used in screening studies and monitoring of oral hygiene and caries in children $[5,7,16,20]$. These studies have expanded the access to dental care and enabled the identification of groups at increased risk of developing oral platelet-related diseases, so-called "diseases of civilization", such as caries and periodontal diseases as well as implementation of the appropriate prophylaxis. The economic aspect and health promotion [6] are not without significance in this situation. In this type of research, attention should also be paid to time-saving due to elimination of the need to travel to a testing site [8].

However, some authors criticize the use of TD as a strategy for expanding access to health services, indicating that the widespread use of TD would be of little benefit compared to conventional screening and preventive programs achieved by dental hygienists [5].

In Latin American countries, such as Brazil, Colombia, and Uruguay, remote medicine has found systemic applications. Implemented information and communications technology (ICT) projects create a part of social dental services, which aim at improving education and co-operation between domestic and foreign facilities [21]. In Brazil, TD is also used to exchange information between universities and practicing primary care dentists, thereby enhancing the value of innovative activi- ties undertaken by scientists and improving the quality of dental care $[4,20,23]$.

In developed countries, which have been using TD technology for a longer time, responses to tele-education indicate $80 \%$ acceptance of this method of education among students and professors, in spite of the potential for the occurrence of certain technical problems during transmission of data $[24,25]$.

In countries, which have used ICT in education to a lesser extent, the pandemic with its need for social isolation have forced a transition to e-learning platforms in order to maintain the continuity of education. Many systems have been utilized to enable real-time teaching, lectures, and even exams, including Pegasus, MS Teams, MS Forms, Zoom, etc. Evaluation of this process is still in progress and will certainly be the subject of many scientific publications in the near future. It is necessary to strongly consider the constantly increasing intensity of the use of distance learning in the future.

It is also worth emphasizing the potential of exchanging experiences and view sharing during digital health seminars, conferences, and congresses. Certain limitations of teledentistry should also be noted. In the case of patient's clinical evaluation, the possibility for physical testing and odor assessment is reduced, while evaluation of non-verbal communication is significantly limited. It may be more difficult, for example, to examine the depth of gingival pockets, the sensitivity to touch, or degree of looseness of hard tissue defects, patency and fistula activity, lymph node examination, soreness, and degree of hardness and displacement relative to the substrate of lesions in the oral mucosa.

One factor that may significantly limit the development of telemedicine and teledentistry networks involves the law of the country in question [26]. Another factor is a lack of sufficient ICT infrastructure, preventing all technological requirements for the provision of relevant services and assurance of the security of patients' data transmission [19, 26, 27].

Another important factor that may limit the rate of development of teledentistry is the human factor.

Dentists with many years of experience who are unfamiliar with new information technologies may experience difficulty in assimilation and usage. It has been shown that a significant number of specialists feel uncertain that their IT skills and knowledge are at a sufficient level [28].

\section{CONCLUSIONS}

Teledentistry reduces costs and restrictions in obtaining access to dental care. It appears as a promising tool enabling easy access to consultations with specialists, especially among patients from dispersion and excluded groups, which can thereby experience improvement in their quality of life. Teledentistry has a great potential 
for the reduction of costs allocated to dental procedures within the healthcare system. This type of remote contact in conditions of social isolation may prove to be one of the most effective methods to support medical care for patients. Moreover, it may facilitate training of medical staff, implementation of pre- and post-graduate curricula, and conducting scientific research.

Finally, it should be emphasized that teledentistry is a modern, multi-dimensional field of dentistry, created as a result of dynamic development of technology. It should become an important component of pre- and post-graduate medical education, as it can play a crucial role in the response to future global and national crises.

\section{CONFLICT OF INTEREST}

The authors declare no potential conflicts of interest with respect to the research, authorship, and/or publication of this article.

\section{References}

1. Maret D, Peters OA, Vaysse F, Vigarios E. Integration of telemedicine into the public health response to COVID-19 must include dentists. Int Endod J 2020; 53: 880-881.

2. Recommendations to be followed when providing dental services in the epidemic in Poland. Available at: https://www.gov.pl/web/ zdrowie/zalecenia-postepowania-przy-udzielaniu-swiadczen stomatologicznych-w-sytuacji-ogloszonego-na-terenie-rzeczypospolitej-polskiej-stanu-epidemii-wzwiazku-z-zakazeniami-wirusem-sars-cov-2.

3. Kvedar J, Coye MJ, Everett W. Connected health: a review of technologies and strategies to improve patient care with telemedicine and telehealth. Health Aff (Millwood) 2014; 33: 194-199.

4. Skelton-Macedo MC, Jacob CH, Ramos DLP, Cardoso RJA, Antoniazzi JH. Teledentistry: aggregate values for the clinician/specialist. Rev Assoc Paul Cir Dent 2012; 66: 95-99.

5. da Costa CB, da Silva Peralta F, Schaefer Ferreira de Mello AL. How has teledentistry been applied in public dental health services? An integrative review. Telemed J E Health 2020; 26: 945-954.

6. Kopycka-Kedzierawski DT, McLaren SW, Billings RJ. Advancement of teledentistry at the University of Rochester's Eastman Institute for Oral Health. Health Aff (Millwood) 2018; 37: 1960-1966.

7. McLaren SW, Kopycka-Kedzierawski DT. Compliance with dental treatment recommendations by rural paediatric patients after a live-video teledentistry consultation: a preliminary report. J Telemed Telecare 2016; 22: 198-202.

8. Vandre RH, Kudryk VL, Fay CR III, Edwards JC Jr, Jones TK. US Army teledentistry. In: Proceedings of the national forum: military telemedicine on-line today; research, practice, and opportunities. New York: IEEE; 1995, p. 53-56.

9. Mandall NA, O'Brien KD, Brady J, Worthington HV, Harvey L. Teledentistry for screening new patient orthodontic referrals. Part 1: a randomised controlled trial. Br Dent J 2005; 199: 659-662.

10. Haron N, Zain RB, Nabillah WM, et al. Mobile phone imaging in low resource settings for early detection of oral cancer and concordance with clinical oral examination. Telemed J E Health 2017; 23: 192-199.

11. Birur PN, Sunny SP, Jena S, et al. Mobile health application for remote oral cancer surveillance. J Am Dent Assoc 2015; 146: 886-894.

12. Nickenig HJ, Wichmann M, Schlegel A, Eitner S. Use of telemedicine for pre-implant dental assessment a comparative study. J Telemed Telecare 2008; 14: 93-97.
13. Simon L, Friedland B. Interstate practice of dental teleradiology in the United States: the effect of licensing requirements on oral and maxillofacial radiologists' practice patterns. Telemed J E Health 2016; 22: 541-545.

14. Ojima M, Hanioka T, Kuboniwa M, Nagata H, Shizukuishi S. Development of web-based intervention system for periodontal health: a pilot study in the workplace. Med Inform Internet Med 2003; 28: 291-298.

15. Queyroux A, Saricassapian B, Herzog D, et al. Accuracy of teledentistry for diagnosing dental pathology using direct examination as a gold standard: results of the Tele-dent Study of older adults living in nursing homes. J Am Med Dir Assoc 2017; 18: 528-532.

16. Kopycka-Kedzierawski DT, Billings RJ. Comparative effectiveness study to assess two examination modalities used to detect dental caries in preschool urban children. Telemed J E Health 2013; 19: 834-840.

17. Intraoral cameras, dental imaging software, and TeleDent teledentistry solutions. Available at: https://www.mouthwatch.com/teledent-software/.

18. Software pre-qualified remotely using the SmileMate assessment tool directly through practice website. Available at: https://www. smilemate.com/.

19. Chen H, Fricton J. Teledentistry: seeing the doctor from a distance. Northwest Dent 2007; 86: 27-28.

20. Carrard VC, Roxo-Goncalves M, Strey JR, et al. Telediagnosis of oral lesions in primary care: the EstomatoNet Program. Oral Dis 2018; 24: 1012-1019.

21. López Jordi MD, Figueiredo MC, Barone D, Pereira C. Study and analysis of information technology in dentistry in Latin American countries. Acta Odontol Latinoam 2016; 29: 14-22.

22. Alkadhi OH, Zahid MN, Almanea RS, Althaqeb HK, Alharbi TH, Ajwa NM. The effect of using mobile applications for improving oral hygine in patients with orthodontic fixed appliances: a randomised controlled trial. J Orthod 2017; 44: 157-163.

23. Pacheco KTS, Nascimento RM, Rios MZ, Filho ACP. Information and communication technologies for professional training in dentistry: a telehealth/ES proposal. Revista da ABENO 2018; 18: 127-136.

24. Schleyer TK, Thyvalikakath TP, Spallek H, Dziabiak MP, Johnson LA From information technology to informatics: the information revolution in dental education. J Dent Educ 2012; 76: 142-153.

25. Correia ADMS, Dobashi BF, Goncalves CCM, et al. Telehealth Brazil Network Program and Teledentistry: experience report of Moto Grosso do Sul, Brazil. J Bras Tele 2015; 2: 87-89.

26. Avula $\mathrm{H}$. Tele-periodontics - oral health care at a grass root level. J Indian Soc Periodontol 2015; 19: 589-592.

27. Bradley M, Black P, Thompson R, Lamey PJ. Application of teledentistry in oral medicine in a community dental service, N. Ireland. Br Dent J 2010; 209: 399-404.

28. Bradley SM, Williams S, D'Cruz J, Vania A. Profiling the interest of general dental practitioners in West Yorkshire in using tele dentistry to obtain advice from orthodontic consultants. Prim Dent Care 2007; 14: 584-589. 